\title{
A construção da política para inclusão de pessoas em situação de rua: avanços e desafios da intersetorialidade nas políticas de saúde $e$ assistência social
}

\section{Developing policies for the inclusion of homeless people: advances and challenges of intersectoriality in health and social assistance policies}

\author{
Alison Oliveira ${ }^{\mathrm{a}}$ \\ (iD) https://orcid.org/0000-0002-0280-8922 \\ E-mail: alisonpo®gmail.com \\ Francini Lube Guizardib \\ (iD) https://orcid.org/0000-0002-5086-4128 \\ E-mail: francini.guizardiळfiocruz.br \\ aSecretaria de Estado de Desenvolvimento Social do Distrito \\ Federal. Brasília, DF, Brasil. \\ ${ }^{\text {b} F u n d a c ̧ a ̃ o ~ O s w a l d o ~ C r u z . ~ E s c o l a ~ F i o c r u z ~ d e ~ G o v e r n o . ~ B r a s i ́ l i a, ~}$ \\ DF, Brasil.
}

\section{Correspondência}

Francini Guizardi

Fiocruz Brasília. Escola Fiocruz de Governo, sala 14.

Universidade de Brasília, Campus Universitário Darcy Ribeiro.

Av. L3 Norte, s/n, Gleba A. Brasília, DF, Brasil CEP 70904-130

\section{Resumo}

O texto tem por objetivo analisar a elaboração da política para inclusão de pessoas em situação de rua, no âmbito das ações de assistência social e saúde no Distrito Federal (DF). De modo específico, busca identificar conflitos; mapear as ações e estratégias desenhadas; e compreender os avanços e desafios que marcaram esse contexto. A pesquisa teve uma abordagem qualitativa, de caráter descritivo, com análise documental e 20 entrevistas semiestruturadas com informantes chave. O material coletado foi analisado com base na abordagem de Stephen Ball sobre do ciclo da política. Os resultados indicam a centralidade e indução da política distrital pela política de assistência social, cujos gestores atuaram de forma verticalizada nos comitês intersetoriais estudados. O contexto da prática, caracterizado como arena de conflito e contestação, revelou o cerceamento do processo decisório e de participação democrática, mantendo-se a hegemonia estatal em sua condução. 0 estudo nos possibilitou identificar a necessidade de dispor de novos desenhos gerenciais visando a produção de respostas intersetoriais ao fenômeno da população em situação de rua no DF.

Palavras-chave: Política Pública; Colaboração Intersetorial; Pessoas em Situação de Rua; Sistema Único de Saúde; Proteção Social. 


\section{Introdução}

This paper analyzes the elaboration of the Policy for Inclusion of Homeless People in Brazil, within the scope of the Social Assistance and Health actions in Distrito Federal. Specifically, the analysis identifies conflicts; traces the actions and strategies adopted; and verifies the advancement and challenges that marked this context. This qualitative study of descriptive character used documentary analysis as methodology and included 20 semi-structured interviews with key informants. The collected material was assessed based on Stephen Ball's approach to the policy cycle. The results indicate the centrality and induction of the district policy by the social assistance policy, whose managers acted in a top-down manner in the studied Intersectoral Committees. The context of the practice, characterized as an arena of conflict and contestation, revealed the closure of the decisionmaking process and of democratic participation, adopting a conduct of state hegemony. A need for new management designs aimed at producing intersectoral measures for homeless people in the Federal District was identified.

Keywords: Public Policy; Intersectoral Collaboration; Homeless People; Unified Health System; Social Protection.
A Política Nacional para a População em Situação de Rua (PNPR), instituída em 2009 pelo Decreto $n^{0} 7.053$, declarou a necessidade de garantir o acesso dessa população às políticas públicas, por meio da gestão intersetorial de serviços e ações governamentais. Essa perspectiva é ancorada na compreensão de que o sujeito em situação de rua "não se fragmenta por suas demandas e necessidades que são muitas e heterogêneas" (Yazbek, 2012, p. 313). Para Silva (2006), tal fenômeno constitui uma síntese de múltiplas determinações, cujas características, incluindo as variações históricas, a tornaram elemento de extraordinária relevância na composição da pobreza nas sociedades capitalistas. A autora elenca três aspectos principais para identificar a população em situação de rua como grupo populacional diferenciado e heterogêneo, reforçando que são condições singulares que se articulam entre si, a saber: (1) pobreza extrema; (2) vínculos familiares interrompidos ou fragilizados; (3) inexistência de moradia convencional regular e a utilização da rua como espaço de moradia e sustento, de modo temporário ou permanente. De forma complementar, relacionamos como uma quarta condição de identificação a invisibilidade perante a sociedade e o poder público.

0 fortalecimento da intervenção estatal com foco na proteção social para a população em situação de rua depende da articulação de diversas áreas e atores no âmbito de cada uma das três esferas da administração pública, em consonância com a Constituição Federal de 1988. Nela, há o indicativo de ações governamentais integradas de modo intersetorial e interinstitucional, como recurso para concretizar o conceito de cidadania assegurado em nossa Carta Magna, o qual constitui uma diretriz para várias políticas públicas destinadas a viabilizar os “direitos sociais: a educação, a saúde, o trabalho, o lazer, a segurança, a previdência social, a proteção à maternidade e à infância e a assistência aos desamparados" (Inojosa, 1998, p. 40). Prates, Prates e Machado (2011) e Araujo (2012) avaliam que, por meio da PNPR, o governo brasileiro avançou nessa direção, propondo-se a intervir de "forma descentralizada e articulada entre a União e os 
demais entes federativos que aderirem por meio de instrumento próprio" (Araujo, 2012, p. 41).

Contudo, a construção efetiva da política pública em análise ocorre como um processo político, como proposto por Kingdon (2003) e por Steven Ball (Mainardes; Marcondes, 2009), em seus respectivos estudos sobre ciclos de políticas. Nessa concepção, embora a ação de governo tenha centralidade, como "política oficial" enunciada em textos políticos e legislativos, a política pública somente ganha materialidade através de uma complexa rede na qual interagem diferentes atores, em um processo político permeado por disputas e convergências de discursos e práticas, que dão forma à política proposta. Nesse sentido, o Estado, mais do que um ente, é considerado como um campo de forças, engendrado pelas relações de poder que conformam tal processo político institucional.

No cenário de construção da PNPR colocam-se desafios como o acesso aos beneficiários e usuários das redes de serviços de cada política, a consecução de estratégias para partilhar metas de enfrentamento das desigualdades sociais, econômicas, regionais e, nelas, as de enfrentamento da pobreza. De modo que, para garantir a atenção necessária às expressões da questão social que tocam a população em situação de rua, a consolidação de novos desenhos gerenciais é fundamental para construir ações intersetoriais entre as políticas sociais. A articulação do Sistema Único de Saúde (SUS) e do Sistema Único de Assistência Social (Suas) é central nesse contexto, e requer a conformação de novos caminhos para a atenção integral a essa população, a fim de que o processo de intervenção promova a saúde em seu conceito ampliado. ${ }^{1}$

O presente texto analisará a elaboração da política para inclusão de pessoas em situação de rua, no âmbito das ações de assistência social e saúde no Distrito Federal (DF). De modo específico, busca identificar conflitos; mapear as ações e estratégias desenhadas; e refletir sobre os avanços e desafios que marcaram esse contexto. Com isso, espera-se que contribua para a compreensão dos processos de integração e desenvolvimento das políticas sociais, em especial, com subsídios para a (re)formulação e proposição de ações intersetoriais destinadas à população em situação de rua.

\section{Método}

A pesquisa se baseou em uma abordagem qualitativa, de caráter descritivo, que buscou analisar a política pública enquanto processo em seu movimento político, na interação entre os elementos componentes e os diferentes contextos históricos. Nesta tarefa, recorremos à perspectiva de Stephen Ball (1993) sobre a abordagem do ciclo da política (Mainardes; Marcondes, 20o9; Rezende; Baptista, 2015).

Para o autor (Ball, 1993), a ideia de que as políticas públicas são implementadas segundo um mecanismo linear e diretivo (agenda, formulação, implementação, avaliação, reformulação) deve ser rejeitada, uma vez que a tradução de políticas públicas em práticas sociais é um processo extremamente complexo. Nessa perspectiva, o mundo das políticas se concretiza por meio de ciclos de repetição, como um campo de conflitos e lutas multifacetadas: lutas sobre valores, interesses e significados, de tal modo que o significado das políticas não é claro, pois decorre de diferentes modalidades de ação, que abrangem, mas também diferenciam, a construção de seus textos normativos e o contexto de suas ações práticas, no sentido de que estas últimas expressam diretamente o fazer (Rezende; Baptista, 2015).

Nesta análise é rejeitada a ideia de uma implementação em direção única, da concepção para a atuação prática (Mainardes; Marcondes, 2009). Ao contrário, compreende que a tradução dos textos primários em ações concretas depende da criatividade e do protagonismo dos sujeitos envolvidos, tornando a implementação

\footnotetext{
1 O conceito ampliado de saúde enfatiza suas relações intrínsecas com as condições de vida das populações, ressaltando suas diferentes dimensões - físicas, psicológicas e sociais, e os complexos processos condicionantes e determinantes de sua produção social. Embora em sua acepção mais corriqueira a atenção integral se refira à garantia de acesso a todos os níveis de atenção necessários para tratamento e reabilitação da saúde, o conceito também abarca outros sentidos da integralidade, que incluem as condições de produção e promoção da saúde. Nessa direção, compreende o aprimoramento das condições de saúde e qualidade de vida, bem como o fortalecimento da autonomia de indivíduos e grupos.
} 
um processo permanente de interpretação e reelaboração da política.

Segundo a formulação teórica de Stephen Ball (1993; Mainardes, Marcondes, 2009) a análise do ciclo das políticas deve contemplar o contexto de influências, o da produção textual e o da prática. Em relação ao primeiro, o autor destaca que as políticas não são apenas de Estados; as instituições mantêm as suas próprias políticas e as pessoas também as possuem. Assim, é necessário entender a dinâmica estabelecida entre elas, sendo impossível pensar política como restrita unicamente à estrutura do Estado. Nessa concepção, as políticas extrapolam o contexto da influência quando sujeitas ao processo de produção de texto, sua tradução e reconstrução. O autor destaca que o processo de ação ocorre com a transformação de um texto em diferentes práticas direcionadas à população. Ele reforça que o problema deste contexto é que as políticas são imaginárias, ou seja, pensadas para atender propostas utópicas, em que há melhores estruturas, melhores profissionais, tudo em modelos ideais, com existência de energia e ideias amplamente disponíveis. No entanto, o mundo real não segue essa lógica, e o processo de interpretação das políticas corresponde em fazer a relação entre as fronteiras dos textos e a realidade cotidiana.

Portanto, o contexto da prática não pode ser pensado de forma simples e linear, já que envolve a resolução de inúmeros conflitos. Ball (1993) chama atenção para o fato de que a implementação envolve empréstimos, apropriação e adaptação, que são feitos por meio de redes e atores estratégicos, envolvidos em colaboração e negociação. Eles fazem as políticas, mas não nas circunstâncias que eles mesmos determinam, pois elas são interpretadas no âmbito das diferentes distribuições de recursos, e sua tradução é um processo de leituras ativas, de representação e reinterpretação de diferentes práticas.

Com isso, reconhecemos a política pública para a população em situação de rua do DF como processo que ocorre de forma não linear, em um movimento institucional e social complexo, que se conforma com a interação entre os elementos da política e os aspectos históricos que a compõem em diferentes contextos.

\section{Procedimentos metodológicos}

Iniciamos a pesquisa em janeiro de 2016 com a coleta e análise de documentos relativos às políticas analisadas. Nesta etapa foram incluídas as orientações técnico-legislativas elaboradas para os eixos do SUS e do Suas, como princípios e estratégias para que estes sistemas programassem ações e serviços públicos, de caráter intersetorial, em atenção à população em situação de rua.

Em seguida foram analisados documentos e registros oriundos dos dois comitês intersetoriais criados pelo Poder Executivo para elaborar e implementar a política destinada à população em situação de rua do DF. Os documentos foram coletados entre janeiro e outubro de 2016. Eles não se encontravam devidamente arquivados e protocolados, motivo pelo qual a busca foi efetuada diretamente pelo pesquisador no acervo da instituição. O Comitê Intersetorial para Elaboração da Política para Inclusão Social da População em Situação de Rua no âmbito do DF (Comitê Pop Rua) foi instituído por meio do Decreto Distrital $n^{0}$ 32.986, de 13 de junho de 2011. Por sua vez, o Decreto Distrital no 33.779, de 6 de julho de 2012, instituiu o Comitê Intersetorial de Acompanhamento e Monitoramento da Política para Inclusão Social da População em Situação de Rua do Distrito Federal (Ciamp Rua), cujas atividades duraram até o mês de março de 2015. Os documentos resgatados foram sistematizados em uma planilha com o detalhamento das informações gerais, assuntos e descritores, seguindo sua organização cronológica. Em seguida os achados foram organizados em diagramas, a fim de reconstituir a linha do tempo do processo político de elaboração da PNPR no DF.

Como método de coleta de dados, utilizamos entrevistas semiestruturadas com atores sociais e políticos relevantes ao estudo (Triviños, 1987), as quais foram realizadas entre janeiro e abril de 2017. Os entrevistados foram identificados a partir da pesquisa documental, nas atas de reunião dos referidos comitês. Todos os representantes que tiveram acento nos comitês das políticas de assistência social, saúde e seus usuários, acrescidos de representantes de políticas públicas com ações e serviços específicos para a população em situação de rua, foram convidados a participar da pesquisa. 
Quadro I-Relação dos entrevistados representantes do Comitê Intersetorial para Elaboração da Política para Inclusão Social da População em Situação de Rua no âmbito do Distrito Federal e do Comitê Intersetorial de Acompanhamento e Monitoramento da Política para Inclusão Social da População em Situação de Rua do Distrito Federal

\begin{tabular}{|c|c|c|}
\hline & Instituição & Representação \\
\hline 1 & $\begin{array}{l}\text { Secretaria de Estado de } \\
\text { Trabalho, Desenvolvimento } \\
\text { Social, Mulher, Igualdade Racial } \\
\text { e Direitos Humanos }\end{array}$ & Governo \\
\hline 2 & $\begin{array}{l}\text { Secretaria de Estado de } \\
\text { Educação do DF }\end{array}$ & Governo \\
\hline 3 & $\begin{array}{l}\text { Secretaria de Estado de Saúde } \\
\text { do DF }\end{array}$ & Governo \\
\hline 4 & Defensoria Pública do DF & Governo \\
\hline 5 & $\begin{array}{l}\text { Movimento Nacional da } \\
\text { População de Rua (DF) }\end{array}$ & $\begin{array}{l}\text { Sociedade } \\
\text { Civil }\end{array}$ \\
\hline 6 & $\begin{array}{l}\text { Grupo de Pesquisa sobre } \\
\text { Tráfico de Pessoas, Violência e } \\
\text { Exploração Sexual de Mulheres, } \\
\text { Crianças e Adolescentes } \\
\text { (Violes/UnB) }\end{array}$ & $\begin{array}{l}\text { Sociedade } \\
\text { Civil }\end{array}$ \\
\hline 7 & $\begin{array}{l}\text { Movimento Nacional de Meninos } \\
\text { e Meninas de Rua (DF) }\end{array}$ & $\begin{array}{l}\text { Sociedade } \\
\text { Civil }\end{array}$ \\
\hline 8 & $\begin{array}{l}\text { Centro de Vivencia Neide } \\
\text { Castanha - Girarte }\end{array}$ & $\begin{array}{l}\text { Sociedade } \\
\text { Civil }\end{array}$ \\
\hline
\end{tabular}

Realizamos em um segundo momento entrevistas semiestruturadas com dirigentes e trabalhadores vinculados à Secretaria de Estado de Saúde do DF e à Secretaria de Estado de Trabalho, Desenvolvimento Social, Mulher, Igualdade Racial e Direitos Humanos. Alguns deles foram identificados como atores estratégicos a partir das entrevistas iniciais, mas também se convidou todos os gestores que respondiam, naquele período, por serviços direcionados à população alvo do estudo. Segundo Rua (2012, p. 38), por vezes são considerados como "atores invisíveis", que atuam como formuladores e implementadores de políticas, e podem afetar fortemente os contextos da política pública, uma vez que contam com recursos significativos de poder, como informação, conhecimento do processo administrativo e político.

Quadro 2 - Relação dos entrevistados vinculados à Secretaria de Estado de Trabalho, Desenvolvimento Social, Mulher, Igualdade Racial e Direitos Humanos Sedest e à Secretaria de Estado de Saúde do Distrito Federal

\begin{tabular}{|c|c|}
\hline & Entrevistados \\
\hline I & Coordenação de Proteção Social Especial \\
\hline 2 & Diretoria dos Serviços de Acolhimento Institucional \\
\hline 3 & $\begin{array}{l}\text { Gerência da Unidade de Acolhimento para Adultos } \\
\text { e Famílias de Taguatinga }\end{array}$ \\
\hline 4 & $\begin{array}{l}\text { Profissional da equipe técnica da Unidade de } \\
\text { Acolhimento para Adultos e Famílias }\end{array}$ \\
\hline 5 & $\begin{array}{l}\text { Gerência da Unidade de Acolhimento para Crianças } \\
\text { e Adolescentes com Vínculo com a Rua }\end{array}$ \\
\hline 6 & $\begin{array}{l}\text { Profissional da equipe técnica da Unidade de } \\
\text { Acolhimento para Crianças e Adolescentes com } \\
\text { Vínculo com a Rua }\end{array}$ \\
\hline 7 & Direção da entidade Casa de Santo André \\
\hline 8 & $\begin{array}{l}\text { Gerência do Centro de Referência Especializado } \\
\text { para a População em Situação de Rua }\end{array}$ \\
\hline 9 & $\begin{array}{l}\text { Profissional da equipe técnica do Centro de } \\
\text { Referência Especializado para a População em } \\
\text { Situação de Rua }\end{array}$ \\
\hline 10 & $\begin{array}{l}\text { Gerência de Atenção à Saúde de Populações em } \\
\text { Situação Vulnerável }\end{array}$ \\
\hline II & $\begin{array}{l}\text { Coordenação Equipe de Consultório de Rua - } \\
\text { Núcleo Brasília }\end{array}$ \\
\hline 12 & $\begin{array}{l}\text { Trabalhador de Equipe de Consultório de Rua - } \\
\text { Núcleo Brasília }\end{array}$ \\
\hline
\end{tabular}

As entrevistas foram integralmente transcritas e o material foi submetido à análise, conforme referencial do Ciclo de Políticas de Stephen Ball. Por fim, foi realizada a sistematização dos achados com os diagramas inicialmente elaborados. A presente pesquisa foi submetida e aprovada pelo Comitê de Ética e Pesquisa da Fundação Fiocruz Brasília, por meio do Parecer $n^{0} 1.789 .758$, 
de 24 de outubro de 2016. 0 estudo apresenta como principal limite o frágil e superficial registro institucional das reuniões dos comitês pesquisados.

\section{Resultados e discussão}

No ano de 2009, o Ministério da Saúde constituiu comitê técnico no intuito de traçar estratégias específicas para a população em situação de rua (Brasil, 2009). Em 2011, por meio do texto da Política Nacional de Atenção Básica (Brasil, 2011), criou-se as equipes de consultório na rua, que produziram efeitos na prática da PNPR, uma vez que elas têm por função a atividade itinerante e ações integradas com as Unidades Básicas de Saúde (UBS); e, consequentemente, buscam romper com as limitações de acesso aos serviços de saúde por parte da população em situação de rua.

Nesse período, o governo do DF buscou reestruturar suas ações destinadas à população em situação de rua. Segundo a representante da Secretaria de Estado de Saúde (SES/DF), seguindo o movimento realizado pelo Ministério da Saúde, a secretaria começou a entender que muito mais interessante seria que as equipes fossem passadas para a atenção básica e que não tivessem mais um enfoque só para a saúde mental (Representação da SES - Ciamp Rua).

Então a gente vem com esse olhar, novo, diferente, ampliado, digamos assim... para a situação clínica, além da situação de drogadição, de transtorno mental, que é o olhar da Saúde Mental, além da questão do abrigamento, da questão social que poderia estar envolvida ou não. (Representação da SES - Ciamp Rua)

A proposta de integração às UBS é o reconhecimento da condição de vulnerabilidade desta população, que necessita de atenção ampliada no campo da saúde pública e das políticas sociais. Os consultórios na rua foram constituídos no âmbito da atenção básica e devem prestar atenção integral de forma itinerante à população, desenvolvendo ações compartilhadas e integradas também com as equipes dos Centros de Atenção Psicossocial (Caps), dos serviços de Urgência e Emergência e de outros pontos de atenção, de acordo com a necessidade do usuário.

O objetivo desta estratégia é que a população em situação de rua acesse a atenção à saúde para além da tradicional precondição de público da saúde mental, assim incorporando atendimentos em outros campos do SUS, por exemplo, atendimento à gestante de rua, tratamento a doenças sexualmente transmissíveis, doenças do trato respiratório, tratamento de doenças de pele, problemas ortopédicos (decorrentes de situação de violência, atropelamento), diabetes, hipertensão, e várias outras situações que necessitam de proteção por parte da política de saúde pública, visando a garantia ao direito à saúde (Brasil, 2012; Santana, 2014).

A gente tinha a oportunidade de poder estar mostrando a questão da importância do cuidado à saúde da população em situação de rua porque os problemas deles são tantos, que as vezes se esquece que eles precisam de cuidar da saúde e a questão da saúde deles é muito importante [...] porque eles vivem em condições insalubres, se expõem ao frio, enfim, a chuva, a precariedade, alimentação inadequada. Tem toda uma situação que favorece o desenvolvimento de determinadas doenças. [...] mas a gente buscou foi a ampliação do olhar mesmo. (Representante da SES no Ciamp Rua)

A baixa articulação dos serviços de atenção à saúde entre si e a sobreposição de suas ações, somadas a sua reduzida resolutividade, foram algumas das limitações que repercutiram diretamente no processo de trabalho concebido pelas equipes de saúde. Por vezes, elas atuaram no limite do processo de saúde e doença, sem correlacioná-los aos fatores determinantes da saúde, ou sem que obtivessem o suporte necessário de ações estruturadas de maneira intersetorial e interinstitucional. Observou-se a recorrência de práticas e concepções preconceituosas sobre a atuação com esta população, o que, consequentemente, impactou negativamente em seu acesso aos serviços de saúde.

existe ainda muito preconceito do serviço, dos nossos serviços de atenção primária, dos centros de saúde, em estar acolhendo essa população. Muitas 
vezes o consultório na rua faz essas abordagens na rua, ou quando eles nos procuram nos Centros POPs, né, e aí então é dado todo um atendimento $e$ depois essas pessoas saem, e não se tem... Às vezes tem a continuidade com a equipe da equipe do consultório na rua, fornecendo medicamentos e determinadas ações. Mas quando depende um pouco de outros níveis da atenção, a gente tem essas barreiras que são enfrentadas e que a gente precisa trabalhar, [...] no sentido de melhorar o acolhimento desses pacientes nos nossos outros serviços, né?! Seja nas emergências, seja nos postos de saúde... Existe essa barreira mesmo e essa dificuldade que a equipe observa. $\varepsilon$ até mesmo dos Caps, que são preparados, vamos dizer assim, pra receber esse tipo de população e, no entanto, também tem resistência. (Gestor da SES)

Segundo Resende e Silva (2014), o DF foi a primeira unidade da Federação a aderir à política nacional por meio da formação de comitê gestor. Em setembro de 2011, após negociação no interior da arena política federal, produziu-se mais uma normativa: a Portaria $n^{0} 77$, de 2 de setembro de 2011 . Essa norma designou os representantes governamentais e não governamentais que influenciaram a formulação do texto da Política para Inclusão Social da População em Situação de Rua no âmbito do DF. Na propositura do Comitê, observamos a preponderância da atuação da então Secretaria de Estado de Desenvolvimento Social e Transferência de Renda do DF (Sedest), ${ }^{2}$ órgão gestor do governo de Brasília, responsável pelo planejamento e pela execução de todos os serviços, públicos e privados, da Política Nacional de Assistência Social (PNAS), vinculada ao então Ministério do Desenvolvimento Social e Combate à Fome (MDS), e responsável pela gestão políticoadministrativa do Suas no DF.

A Sedest esteve no comando e na coordenação do processo político do referido comitê intersetorial, influenciando diretamente sua composição e, em consequência, as direções e os caminhos por ele propostos. Isto porque a Secretaria de Estado mantevese como coordenadora do comitê, por competência dada pelo Decreto Distrital n ${ }^{0}$ 32.986/2011, e teve autonomia sobre a indicação e designação dos representantes que o conformaram. Tal fato influenciou diretamente o resultado do grupo de trabalho, reproduzindo relações políticas prévias com os demais atores sociais e políticos interessados na temática da população em situação de rua, tais quais entidades da sociedade civil e órgãos públicos do DF.

Art. $3^{\circ} \mathrm{O}$ Comitê Intersetorial será coordenado pela Secretaria de Estado de Desenvolvimento Social e Transferência de Renda.

Parágrafo único. O coordenador do Comitê Intersetorial poderá convidar para participar de suas reuniões, representantes de outros órgãos e entidades da Administração Pública Federal, do Distrito Federal, dos Estados e dos Municípios, dos Poderes Judiciário e Legislativo, de entidades privadas sem fins lucrativos, bem como especialistas afins.

Art. $4^{\circ} \mathrm{A}$ designação dos representantes dos órgãos e entidades citados no artigo $2^{\circ}$ dar-se-á por Portaria do Secretário de Estado de Governo. (Distrito Federal, 2011, grifo nosso)

A Sedest possui representatividade perante a população em geral, e sobretudo a população em situação de rua, tendo em vista sua grande capilaridade e a inserção de seus serviços em todo o território do DF. Ela tem a característica política de atuar de forma conjunta com outras instituições e(ou) políticas públicas no trato da questão social e suas expressões. Nesse sentido, destaca-se sua atuação na política, seus discursos e interpretações da questão social, e produção dos textos políticos com a formulação de determinados padrões de significação, os quais conferem sentido e legitimam regras, sistemas simbólicos, cognitivos e modelos morais enquanto elementos estratégicos para o exercício da política pública (Ball, 1993).

\footnotetext{
2 Denominação dada a Secretaria de Estado no período de instituição dos comitês intersetoriais analisados no presente estudo. Devido a processos políticos, durante o presente estudo a Secretaria manteve a denominação de Secretaria de Estado de Trabalho, Desenvolvimento Social, Mulher, Igualdade Racial e Direitos Humanos (SEDESTMIDH), porém na atual conjuntura política o órgão gestor da política de assistência social é denominado Secretaria de Estado de Desenvolvimento Social (Sedes).
} 
A representante do Movimento Nacional de Meninas e Meninos de Rua enfatiza ainda que os representantes da Associação de Catadores de Materiais Recicláveis (Catamare) e ocupações compuseram o Ciamp Rua por influência da presidente do Movimento Nacional da População de Rua do DF, que à época também era parte da cooperativa de materiais reciclados e demandante pela regularização de áreas de ocupação irregular no intuito de garantir o acesso à habitação. Tal composição do comitê decorreu de relações mantidas com a gestão da Sedest, cuja indicação para representação da sociedade civil no comitê contemplou atores sociais com quem mantinha relações políticas construídas por pautas anteriores.

A gente [gestão da Sedest] também tinha muita relação com eles [lideranças do MNPR], por conta de todo processo com a Catamare [...] toda relação com os catadores de material reciclável [...] que foi uma gestão que se aproximou muito desse público. Então, a gente fez uma discussão com eles e montou um decreto. Agora a participação do movimento de população em situação de rua, ela foi muito importante em todos os momentos, não foi uma coisa que a Sedest pensou e disse: Ah, vamos fazer a política, vamos criar o comitê e tal e chamou a sociedade civil pra dialogar e vamos compor. (Entrevistado da Sedest)

A Política Pública para Inclusão Social da População em Situação de Rua do Distrito Federal sofreu influência direta da PNPR em sua natureza e forma textual, praticamente com breves alterações do normativo inspirador. Um ano após ter sido formado o Comitê Pop Rua ocorreu a instrução da Política para Inclusão Social da População em Situação de Rua do DF, dada por meio do Decreto Distrital $\mathrm{n}^{0}$ 33.779, de 6 de julho de 2012. Este decreto regulou a ação prática de implementação e instituiu o Ciamp Rua, com vistas a "implantar políticas públicas de forma intersetorial e transversal, garantindo a estruturação da rede de proteção às pessoas em situação de rua" (Distrito Federal, 2012).

O período compreendido entre a elaboração da política distrital no Comitê Pop Rua e sua execução e monitoramento, feito pelo Ciamp Rua, representou um processo de articulação entre os grupos de interesse envoltos ao tema da população em situação de rua no DF. De um lado, as diferentes Secretarias de Estado do DF, com interesses e avaliações políticas sobre a relevância e os significados do processo; e de outro, instituições sociais que atuavam junto à população e aos usuários, as quais buscavam espaços de escuta sobre as condições e necessidades desta população. Presumimos que as instituições sociais também buscavam liderar a construção distrital da política, com a perspectiva de possíveis ganhos de representatividade, ou de melhores condições e oportunidades de firmar convênios com as Secretarias de Estado participantes do esforço intersetorial.

Durante tal período, o Comitê Pop Rua realizou 11 reuniões ordinárias, de 2 de setembro de 2011 a 2 de fevereiro de 2012, e construiu a proposta de Política Distrital, a qual foi publicada, como vimos, apenas em julho de 2012. No entanto, há de se observar que as atividades desempenhadas para a elaboração da Política Distrital não seguiram um processo de construção claro ou dinamizado entre os representantes do Comitê Pop Rua.

Tendo em vista que a proposição central da política distrital é a garantia de estruturação da rede de proteção social para a população em situação de rua no DF, por meio da articulação de políticas intersetoriais inferimos que os resultados do processo expressam preponderância da Sedest em sua elaboração normativa. Tal fato repercutiu negativamente na pluralidade e na articulação intersetorial que a composição do Comitê Pop Rua buscava garantir. A repetição do texto da política federal prejudicou a incorporação das especificidades locais, o processo de composição de forças, interesses e posicionamentos, que caracterizam a formação social e política do DF.

A gente tinha a Política Nacional, a gente olhava a Política Nacional e a gente falava: "Bom, está bom. Esse aqui éo nosso teto, né?! Isso aqui vai estarna nossa política. Mas, o que a gente pode detalhar um pouco melhor considerando a realidade do DF, e o que a consegue colocar mais". Então de fato aquelas Políticas onde infelizmente a gente ainda não conseguiu influenciar tanto, onde a gente não 
tem acumulo de debate, como cultura... a gente pouco fala sobre isso. [...] A gente meio que copiou da Política Nacional. (Representante da Sedest Comitê Pop Rua)

A pouca preocupação com a propositura de uma política distrital que fosse objeto de trabalho conjunto e articulado dos atores representados no comitê intersetorial ficou saliente nas entrevistas com os representantes governamentais, em particular os da Sedest. Seus gestores foram categóricos em afirmar que a dinâmica de funcionalidade do comitê era olhar a PNPR e copiar as orientações existentes no âmbito nacional, seguindo-se a justificativa que o DF não detinha acúmulo sobre esta pauta. Com isso, o comitê intersetorial, sob a coordenação da Sedest, não observou o processo de sua composição, os fluxos existentes entre as políticas e atores; assim como não expressou a abertura e sensibilidade da agenda governamental distrital para novas pautas. Os gestores entrevistados salientaram que a construção da PNPR foi materializada a partir do processo de organização e reivindicação dos atores e instituições sociais que atuavam com população em situação de rua e, no caso do DF, que a construção foi muito mais direcionada para a atenção aos fatores governamentais e aspectos do campo gerencial da política pública.

Neste contexto, observamos que a estratégica de gestão da Sedest foi coordenar todo o processo de implementação e execução da política. A secretaria coordenou tanto o comitê de elaboração da política quanto o comitê de monitoramento, o que a fez estar presente em todos os atos e ações da arena política de negociação. A função de coordenação dos comitês intersetoriais, por sua natureza e competência, tem condições de influenciar a construção dos normativos da política, assim como participa de todo o processo de negociação e destinação de ações práticas.

Então, naquela época, nós selecionamos, na verdade identificamos as secretarias que trabalhavam mais com população em situação de rua a época e também com instituições da sociedade civil. Então era um comitê paritário, né!? Na verdade, até a construção do comitê, ela foi discutida com a sociedade civil... Então por mais que fosse uma instância de trabalho coordenada pela Sedest na época, ela tinha participação intensa... Nós fizemos o decreto... Nós que puxamos a sociedade civil... Na época, a gente tinha muita relação com o movimento de meninos e meninas em situação de rua. (Representante da Sedest - Comitê POP RUA)

A morosidade de quase seis meses para indicar os representantes do governo e da sociedade civil para compor o Ciamp Rua, feita por meio da Portaria ${ }^{0} 29$, de 13 de dezembro de 2012, caracteriza a resposta gerencial ao processo de formulação e articulação da política, que tem em sua estrutura a coordenação das ações vinculadas a apenas um órgão setorial.

Embora fosse necessária a existência deste órgão com capacidade de interlocução para agregar ações e serviços, registra-se que estes foram concebidos separadamente e inseridos institucionalmente em vários órgãos do governo do DF. Nesse sentido, é preciso um espaço legítimo para se colocar em prática uma gestão administrativa que garanta a integração e a visibilidade ao conjunto de ações e serviços destinados à população em situação de rua.

Mas a gente sempre dizia que por esse comitê por ser extremamente intersetorial e aífica no colo da assistência o poder mesmo do comitê fica restrito. Porque quem é a Secretaria Assistência Social pra cobrar ou articular com outra secretaria? Ela tem esse papel, mas o poder institucional que ela tem pra isso é um pouco limitado, não resolve muito isso. (Representante da Sedest - Comitê Pop Rua)

Dentre as unidades de gestão setorial, destacamos os relatos da Sedest, da Secretaria de Saúde e da Secretaria de Educação, que já desempenhavam atividades e ações destinadas diretamente à população em situação de rua do DF. Contudo, segundo os gestores destas pastas governamentais, com a implementação da política distrital não se observa um processo significativo de reformulação, avanço ou inovação das práticas anteriormente realizadas.

Nas entrevistas colhidas há reflexões bastante simétricas entre os períodos de elaboração e implementação da política para a população em 
situação de rua, assim como exposição sobre limitações no campo da gestão de pessoas. O efetivo de servidores é considerado restrito, quando comparado à necessidade da oferta de serviços e ações públicas. Eles também expõem elementos que agregam potencialidades ao processo, como a garantia de execução das políticas públicas por seus agentes, produzindo efeitos a partir de seus modos de regulação e da execução das políticas setoriais.

A gente tinha 15 educadores fazendo abordagem em Brasília inteira e a gente tinha os equipamentos de consultório na rua e de Caps bastante reduzidos. o comitê e a Política indicavam uma necessidade de ampliar esses equipamentos, principalmente esses: abordagem social, consultório na rua, Caps e unidade de acolhimento. (Representante Sedest Comitê Pop Rua)

No caso da Secretaria de Estado de Saúde do DF, a gestora revela limitações observadas durante o movimento de elaboração e implementação da política. Estas limitações concernem às relações de gestão e aos interesses intersetoriais vigentes na arena política, fato também expresso pela representante da sociedade civil ao revelar o afastamento de pautas em detrimento de ações tecnicistas e burocratizadas, conduzidas no interior do comitê intersetorial.

De princípio a gente sentiu bastante dificuldade porque era algo muito técnico, você queria colocar pessoas do movimento, pessoas ali da sociedade civil para estar colaborando, participando, vendo como monitorar, melhorar a política da população em situação de rua, mas era algo extremamente técnico. A gente passou várias reuniões discutindo o regimento interno, a ata de abertura ... sabe, questões assim... estava um pouco empacado assim... depois de muitas discursões a gente conseguiu abrir essas pautas e conseguimos. O movimento ficava ali de corpo presente, sem entender o que era tratado, muito termo técnico. (Representante da sociedade civil - Comitê Pop Rua)

No caso da Secretaria de Educação do DF, a representante no comitê intersetorial para a elaboração da política apontou que o processo explicitou as segmentações institucionais sobre as funções e especificidades setoriais, com pouco avanço na articulação e composição intersetorial de novas ações destinadas a essa população. Os representantes governamentais consideraram que os comitês proporcionaram a formulação de ações práticas, que incidiram na construção de estratégias políticas para a estruturação da rede de proteção do DF, como: a formulação de dois Centros de Atendimento à População em Situação de Rua; o conveniamento de instituições sociais para a execução de serviço de abordagem social em espaços públicos e de acolhimento institucional, ambos vinculados à política de assistência social; a consolidação de dois núcleos de consultório na rua, vinculados à política de saúde; e a abertura de espaço de representatividade para movimentos e/ou grupos sociais não visíveis em outras arenas políticas, como o próprio comitê intersetorial de monitoramento das políticas.

A crítica ao processo de centralização e a busca pela consolidação do modelo intersetorial, propostos pela PNPR, fazem com que a condução do processo efetivada pela Sedest apresente elementos contraditórios ao direcionamento estabelecido nacionalmente e referenciado no DF. Salientamos que a intersetorialidade não pode ser considerada antagônica ou substitutiva da setorialidade. Para tanto, o modelo de gestão intersetorial tem que ser "factível quando combinado à descentralização territorial" das ações direcionadas à população (Sposati, 2006, p. 135). A intersetorialidade consiste, assim, em uma estratégia construída para a integração e/ou complementação de uma ação em rede, em determinada área físico-territorial de abrangência. No caso da população em situação de rua, as características e as demandas de um território (dinâmica, cidadãos, natureza) determinarão a extensão e a intensidade da intersetorialidade diante da proposta de integração com a população. O processo analisado expõe importantes limites dos canais institucionais criados para elaboração e monitoramento da política distrital, que não atenderam a necessidade de integração com o modelo de representação e de gestão propostos nos comitês intersetoriais. 


\section{Considerações finais}

O presente estudo analisou a construção da política para a população em situação de rua, no âmbito das ações de assistência social e saúde no DF. O percurso teórico-metodológico utilizado partiu da compreensão de que o fenômeno da população em situação de rua deve ser observado em seu complexo e contraditório processo de produção e reprodução social.

As políticas sociais enfocadas neste estudo, de forma antagônica à concepção e direção apresentada na seguridade social brasileira, induziram, no âmbito do DF, reduzidas ou inexistentes ações de proteção social à população em situação de rua. A "incondicionalidade" e a "universalidade" propostas pela seguridade social na Constituição Federal não se efetivaram como esperado na capital federal, uma vez que, com exceção de poucas ações específicas, as políticas sociais implicadas privilegiaram intervenções focais e a despolitização do processo de construção social da política pública.

O processo de construção da PNPR pode ser entendido como reflexo de disputas entre grupos de interesses governamentais e sociais, que atuaram na arena política e que contribuíram diretamente para a produção dos textos apresentados, assim como em ações práticas da política. Nesse sentido, reforçamos que o contexto da influência é sistematicamente recolocado como reprodutor dos processos ideológicos e de poder, não apenas da PNPR, mas da interface com as demais políticas pertinentes à questão social.

Nesse sentido, os dados analisados indicam a centralidade e indução da política distrital pela política de assistência social, que atuou de forma verticalizada nos comitês intersetoriais (tanto de elaboração, quanto de monitoramento da política distrital) em suas relações institucionais e administrativas. Tal atuação sobre os jogos e embates presentes na concepção da política direcionaram a um incipiente processo de articulação e diálogo das representações do poder público e da sociedade civil para a estruturação de rede de proteção social de caráter intersetorial. Essa condição repercute diretamente na política distrital, uma vez que, embora a representação da sociedade civil tenha sido inserida sob as prerrogativas legais em relação à paridade no Ciamp Rua, não obteve condições de validar suas estratégias ou mesmo garantir que as demandas apresentadas por suas representações encontrassem resolutividade ou inserção dentro da agenda pública. $O$ contexto da prática, caracterizado como arena de conflito e contestação, revelou o cerceamento do processo decisório e de participação democrática, mantendo-se a hegemonia estatal em sua condução.

Por fim, avançando-se sobre o esforço analítico em sistematizar e compreender a política nacional para a população em situação de rua no DF, dentro da lógica contraditória das relações sociais, econômicas e políticas da capital federal brasileira, percebemos que o estudo nos possibilitou vislumbrar certa funcionalidade da política em suas destinações e tendências. Nesse sentido, reconhece-se a necessidade em conceber novos espaços democráticos para tencionar o Estado, distintos dos utilizados no processo de construção e consolidação da política distrital, assim como a necessidade de dispor de novos desenhos gerenciais para a política de inclusão da população em situação de rua do DF, visando a produção de respostas intersetoriais ao fenômeno da população em situação de rua e ao enfrentamento da pobreza como sua expressão social.

\section{Referências}

\section{ARAUJO, V. F. C. Política nacional para a}

população em situação de rua: breve análise. 2012. Trabalho de Conclusão de Curso (Bacharelado em Gestão de Políticas Públicas) - Universidade Federal do Rio Grande do Norte, Natal, 2012.

BALL, S. What is policy? Texts, trajectories and toolboxes. Discourse, Londres, v. 13, n. 2, p. 10-17, 1993.

BRASIL. Portaria $\mathrm{n}^{\circ} 3 \cdot 305$, de 24 de dezembro de 2009. Institui o Comitê Técnico de Saúde para a População em Situação de Rua. Diário Oficial da] União, Brasília, DF, 24 dez. 20og. Disponível em: <https://bit.ly/2UERlgs>. Acesso em: 6 jun. 2019.

BRASIL. Portaria $\mathrm{n}^{\circ} \mathbf{2 . 4 8 8}$, de 21 de outubro de 2011. Aprova a Política Nacional de Atenção Básica, estabelecendo a revisão de diretrizes e normas para 
a organização da Atenção Básica, para a Estratégia Saúde da Família (ESF) e o Programa de Agentes Comunitários de Saúde (PACS). Diário Oficial da União, Brasília, DF, 21 out. 2011. Disponível em: <https://bit.ly/3cXdJRB . Acesso em: 6 jun. 2019.

BRASIL. Ministério da Saúde. Secretaria de Atenção à Saúde. Departamento de Atenção Básica. Manual sobre o cuidado à saúde junto à população em situação de rua. Brasília, DF, 2012. (Série A, Normas e Manuais Técnicos).

DISTRITO FEDERAL. Decreto Distrital nº 32.986, de 13 de junho de 2011. Diário Oficial do Distrito Federal, 14 jun. 2011. Seção 1, p. 44.

DISTRITO FEDERAL. Decreto n ${ }^{0} 33.779$, de o6 de julho de 2012. Diário Oficial do Distrito Federal, 9 jul. 2012. Seção 1, p. 62.

INOJOSA, R. M. Intersetorialidade e a configuração de um novo paradigma organizacional. Revista de Administração Pública, Rio de Janeiro, v. 32, n. 2, p. 35-48, 1998.

KINGDON, J. W. Agendas, alternatives and public policies. 2. ed. Ann Arbor: University of Michigan, 2003.

MAINARDES, J.; MARCONDES, M. I. Entrevista com Stephen J. Ball: um diálogo sobre justiça social, pesquisa e política educacional. Educação \& Sociedade, Campinas, v. 30, n. 106, p. 303-318, 2009.

PRATES, J. C.; PRATES, F. C.; MACHADO, S. População em situação de rua: os processos de exclusão e inclusão precária vivenciados por esse segmento. Temporalis, Brasília, DF, v. 11. n. 22, p. 191-215, 2011.

RESENDE, M. V.; SILVA, R. B. Políticas públicas à situação de rua, discurso e (im)possibilidades de participação da sociedade civil: um caso no CIAMPRUA/DF. In: Simpósio Nacional sobre Democracia e Desigualdades, 2., 7-9 maio 2014, Brasília, DF. Anais... Brasília, DF: Demodê, 2014.

REZENDE, M.; BAPTISTA, T. F. A Análise da política proposta por Ball. In: MATTOS, R. A.; BAPTISTA, T. W. F. (Org.). Caminhos para análise das políticas de saúde. Porto Alegre: Rede Unida, 2015. p. 273-284.
RUA, M. G. Políticas públicas. 2. ed. Santa Catarina: UFSC; 2012.

SANTANA, C. Consultórios de rua ou na rua? Reflexões sobre políticas de abordagem à saúde da população de rua. Cadernos de Saúde Pública, Rio de Janeiro, v. 30, n. 8 p. 1798-18oo, 2014.

SILVA, M. L. L. Mudanças recentes no mundo do trabalho e o fenômeno população em situação de rua no Brasil 1995-2005. 2006. Dissertação (Mestrado em Política Social) - Universidade de Brasília, Brasília, DF, 2006.

SPOSATI, A. Gestão pública intersetorial: sim ou não? Comentários de experiência. Serviço Social \& Sociedade, São Paulo, n. 85, p. 133-141, 2006.

TRIVIÑOS, A. N. S. Introdução à pesquisa em ciências sociais: a pesquisa qualitativa em educação. São Paulo: Atlas; 1987.

YAZBEK, M. C. Pobreza no Brasil contemporâneo e formas de seu enfrentamento. Serviço Social \& Sociedade, São Paulo, v. 110, p. 288-322, 2012.

\section{Contribuição dos autores}

Alison Oliveira participou do delineamento da pesquisa, coleta de dados, análise do material, redação, revisão crítica e aprovação da versão final do artigo. Francini Lube Guizardi participou do delineamento da pesquisa, análise do material, redação, revisão crítica e aprovação da versão final do artigo.

Recebido: 27/10/2019

Aprovado: 02/06/2020 